\title{
DEVELOPMENT OF PHOTOCATALYSTS FOR THE DEGRADATION OF EMERGING CONTAMINANTS IN WATER
}

CINDECA

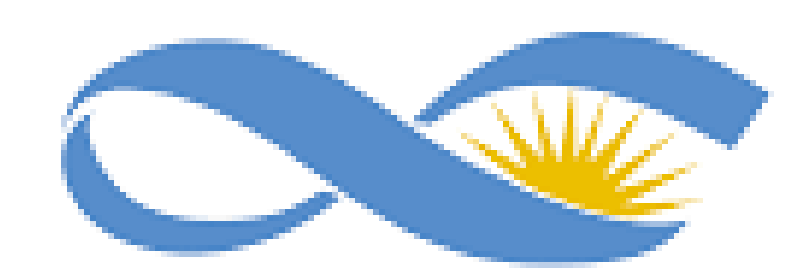

CONICET

\begin{tabular}{lllll}
\hline$U$ & $N$ & L & P
\end{tabular}

\section{Espinosa J. Karolth R.a,b, Villabrille Paula I. b, Caregnato Paulaa}

a Instituto de Investigaciones Fisicoquímicas Teóricas y Aplicadas (INIFTA), Facultad de Ciencias Exactas, Universidad Nacional de La Plata, CCT La PlataCONICET, La Plata, Argentina.

"Centro de Investigación y Desarrollo en Ciencias Aplicadas "Dr. Jorge J. Ronco" (CINDECA), Facultad de Ciencias Exactas, Universidad Nacional de La Plata, CCT La Plata-CONICET, La Plata, Argentina.

\section{INTRODUCTION}

The presence of emergent contaminants (EC), such as pharmaceuticals, in aqueous media is a serious and unresolved concern. Carbamazepine (CBZ) is a highly persistent antiepileptic drug that is resistant to biodegradation. The effect of CBZ on aquatic life has been evaluated as dangerous ${ }^{1}$.

The use of $\mathrm{ZnO}$ as a photocatalyst has been widely used for the degradation of contaminants in water due to its low toxicity, low relative cost and wide bandgap. However, it presents a rapid recombination of photogenerated electrons and holes, which added to photocorrosion, could decrease its photocatalytic activity ${ }^{2-4}$.

Modifying ZnO with metals allows to overcome these limitations, as well as visible light absorption.

\section{MATERIALS AND METHODS}

\section{Sol-gel method \\ Synthesis \\ Zinc Oxide: $\mathrm{ZnO}$}

Zinc oxide doped with

5 at\% $\mathrm{Ce}(\mathrm{pH} 4): \mathrm{CeZnOa}$

Zinc oxide doped with

5 at\% $\mathrm{Ce}(\mathrm{pH} 8)$ : $\mathrm{CeZnOb}$
Characterization

- RAMAN

- FTIR

- SEM

- HRTEM
- Phenol $1 \times 10^{-4} \mathrm{M}$

- Carbamazepine (CBZ) $6.3 \times 10^{-5} \mathrm{M}$

- Catalyst $1 \mathrm{~g} / \mathrm{L}$

\section{RESULTS AND DISCUSSION}

Fig. 1. Raman spectra of $\mathrm{ZnO}, \mathrm{CeZnOa}$, and $\mathrm{CeZnOb}$ catalysts.

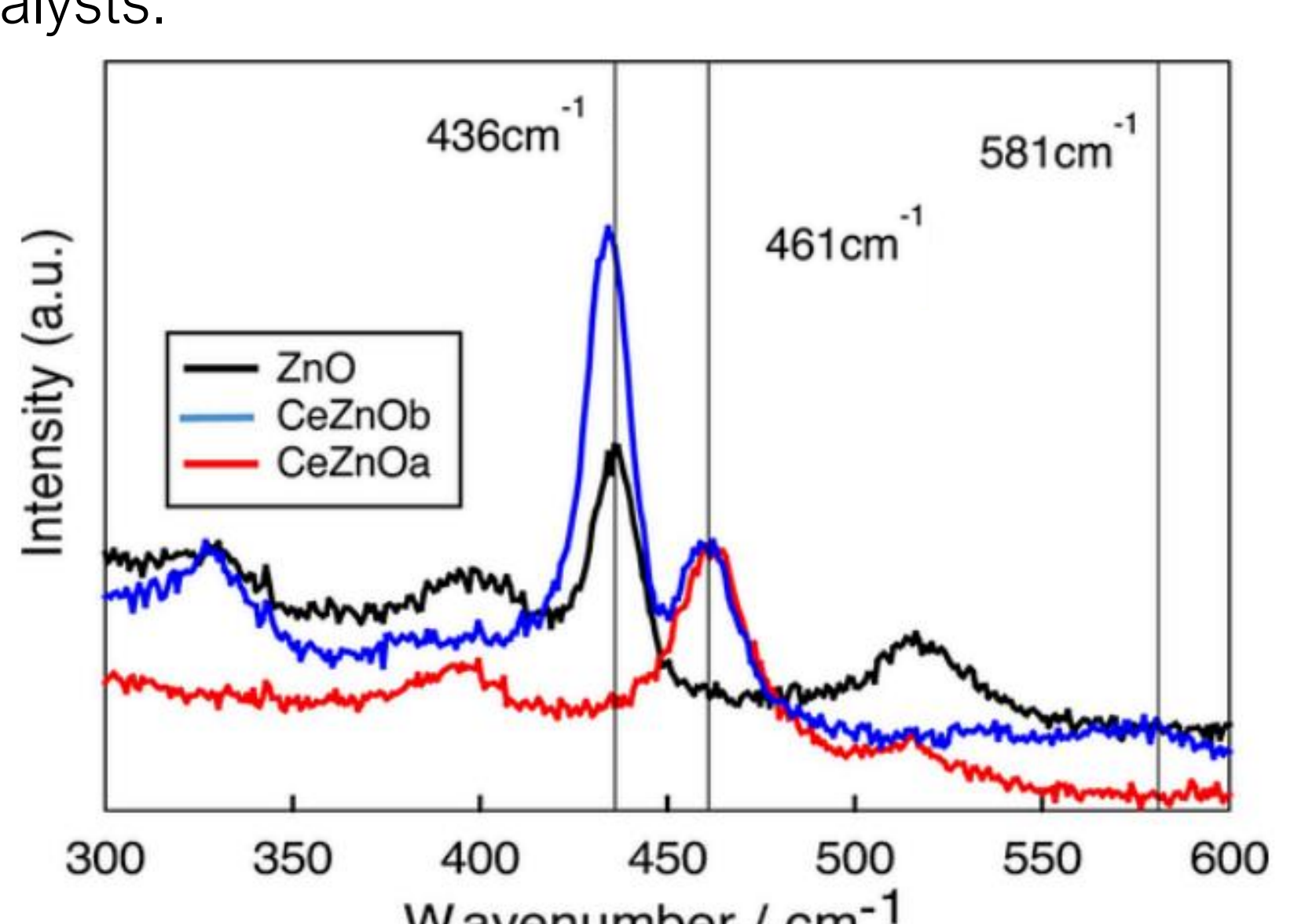

$436.3 \mathrm{~cm}^{-1}$ wurtzite phase of $\mathrm{ZnO}$

$461 \mathrm{~cm}^{-1}$ cubic structure of $\mathrm{CeO}_{2}$ fluorite

$581 \mathrm{~cm}^{-1}$ defects such as oxygen vacancies and interstitial Zn

Fig. 2. FTIR spectra of ZnO, CeZnOa, and $\mathrm{CeZnOb}$ catalysts.

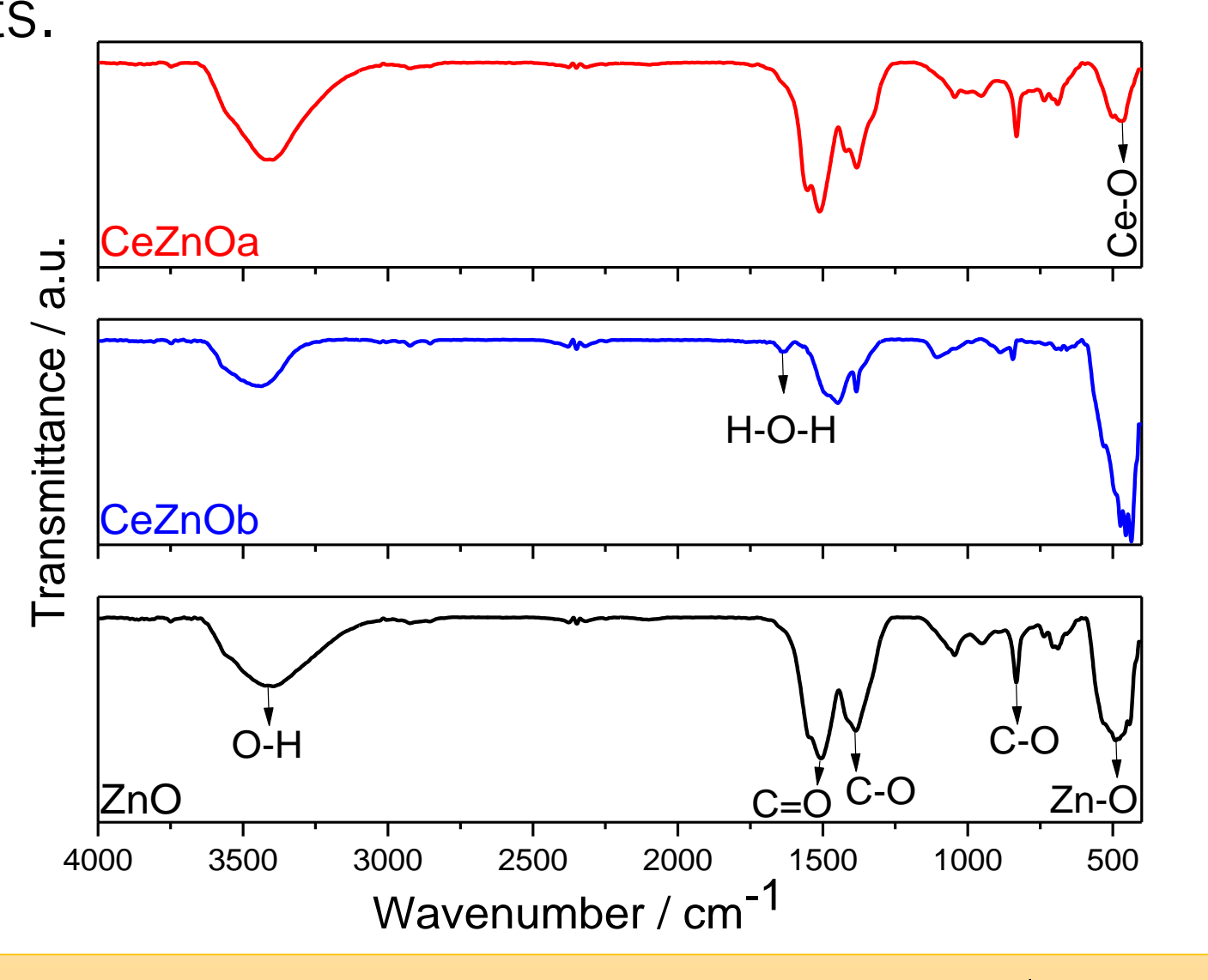

Intense band in the range of $600-400 \mathrm{~cm}^{-1}$ contributions from the stretching modes of $\mathrm{Zn}-\mathrm{O}$ and $\mathrm{Ce}-\mathrm{O}$.

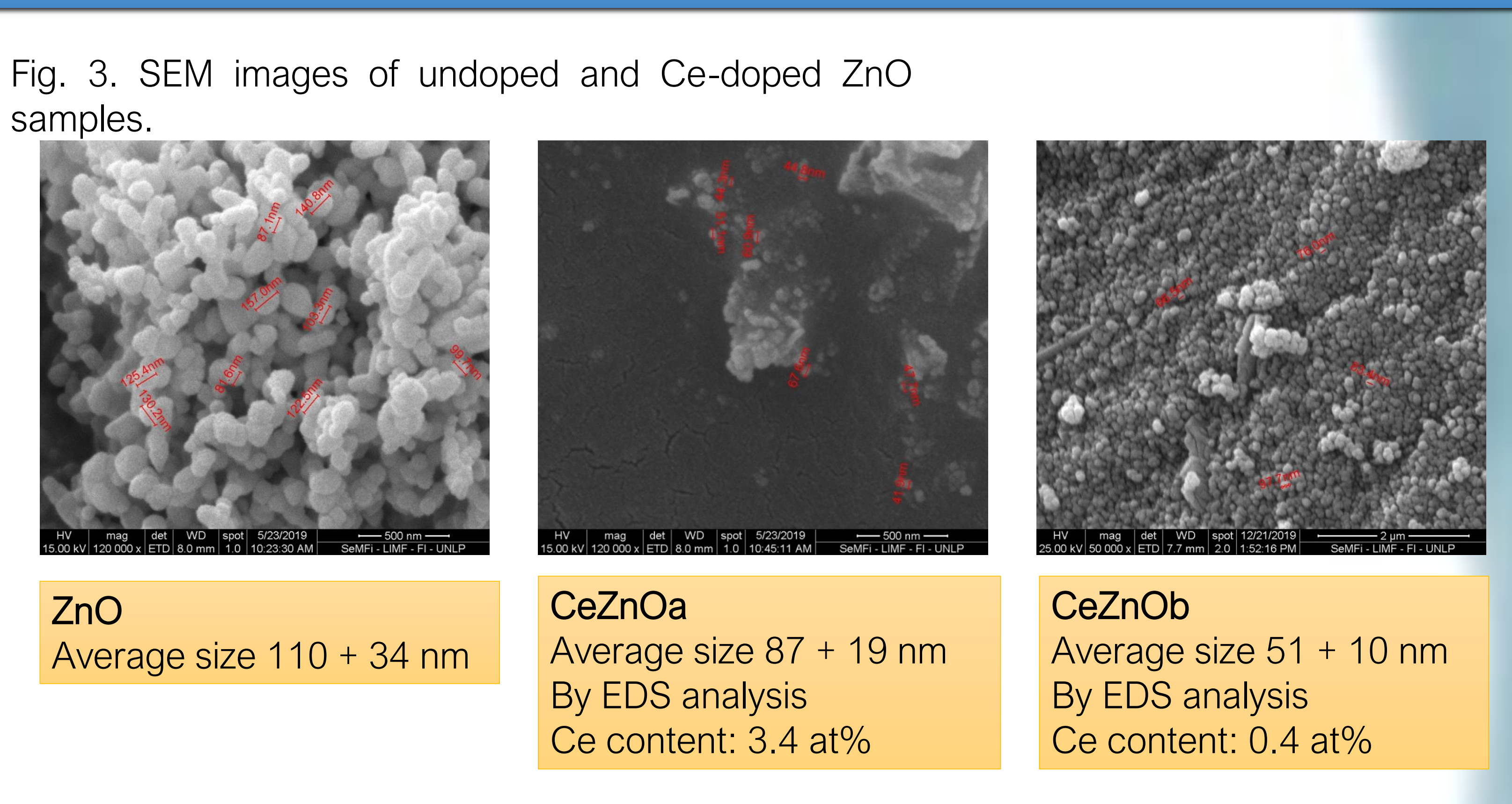

Fig. 4. TEM images of undoped and Ce-doped $\mathrm{ZnO}$ samples.
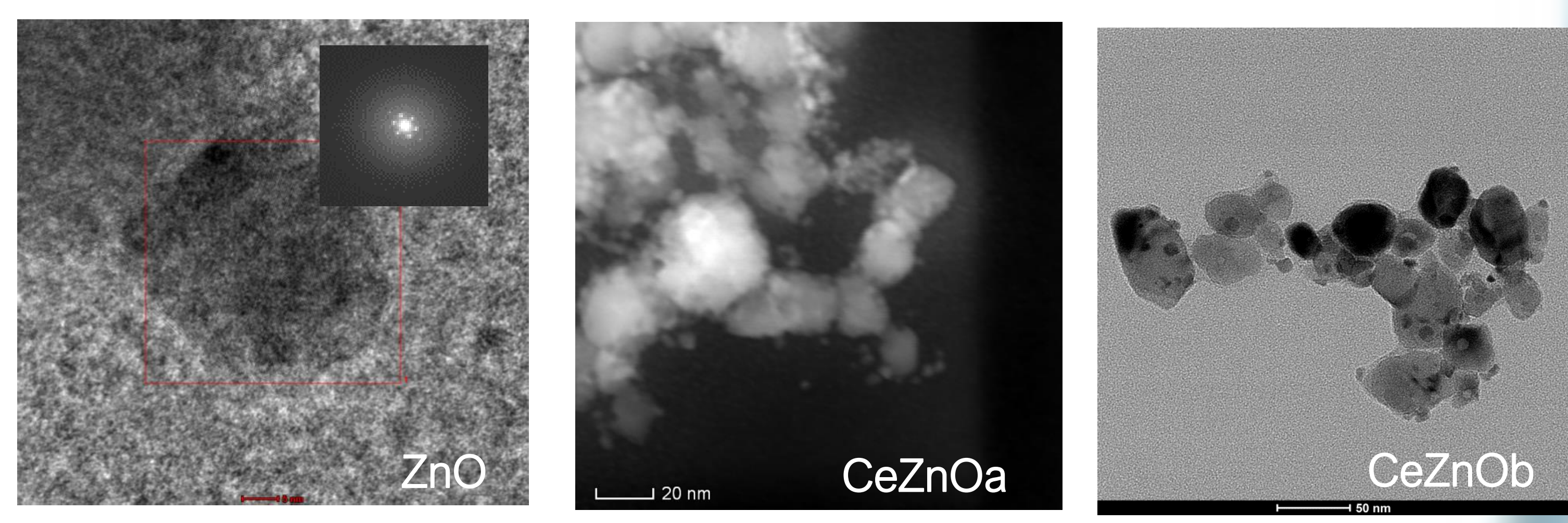

ZnO TEM images mainly show polyhedral particles with sizes in the range of $100-50 \mathrm{~nm}$, an essentially crystalline nature is observed.

Ce-doped $\mathrm{ZnO}: \mathrm{ZnO}$ particles with a diameter of $\sim 50 \mathrm{~nm}$ and smaller particles of size 5 $\mathrm{nm}$, which are identified as $\mathrm{CeO}_{2}$, At acid pH some of them forming agglomerates.

\section{CONCLUSIONS}

Two Ce-dopped ZnO photocatalysts were prepared at pH 4 and 8 using a simple wet method, with different structural, morphological, and surface properties.

They decrease the photodissolution of zinc in the aqueous media with respect to the undoped catalyst, in the experimental conditions described ${ }^{5}$.

The Ce-doped ZnO catalyst synthesized at pH 8 showed a good photocatalytic performance for carbamazepine and phenol degradation (> $45 \%$ ) after $3 \mathrm{~h}$ of irradiation with visible light.

\section{OBJECTIVES}

* Perform the synthesis and characterization of undoped and Ce-doped $\mathrm{ZnO}$ by sol-gel method, at pH 4 and pH 8.

* Evaluate the photocatalytic activity of the as prepared materials for the degradation of phenol (as model of organic pollutant) and carbamazepine using UV and visible irradiation.

\section{Photocatalytic Activity}

$3 \mathrm{~h}$ of photolysis - Contaminants evolution by HPLC

Photolysis Rayonet Reactor

- 8 UV lamps (365 nm)

- 8 Visible lamps (575 $\mathrm{nm})$
Fig. 5. Percentage of phenol and CBZ degradation with the prepared catalysts after $3 \mathrm{~h}$ of irradiation with $575 \mathrm{~nm}$ lamps

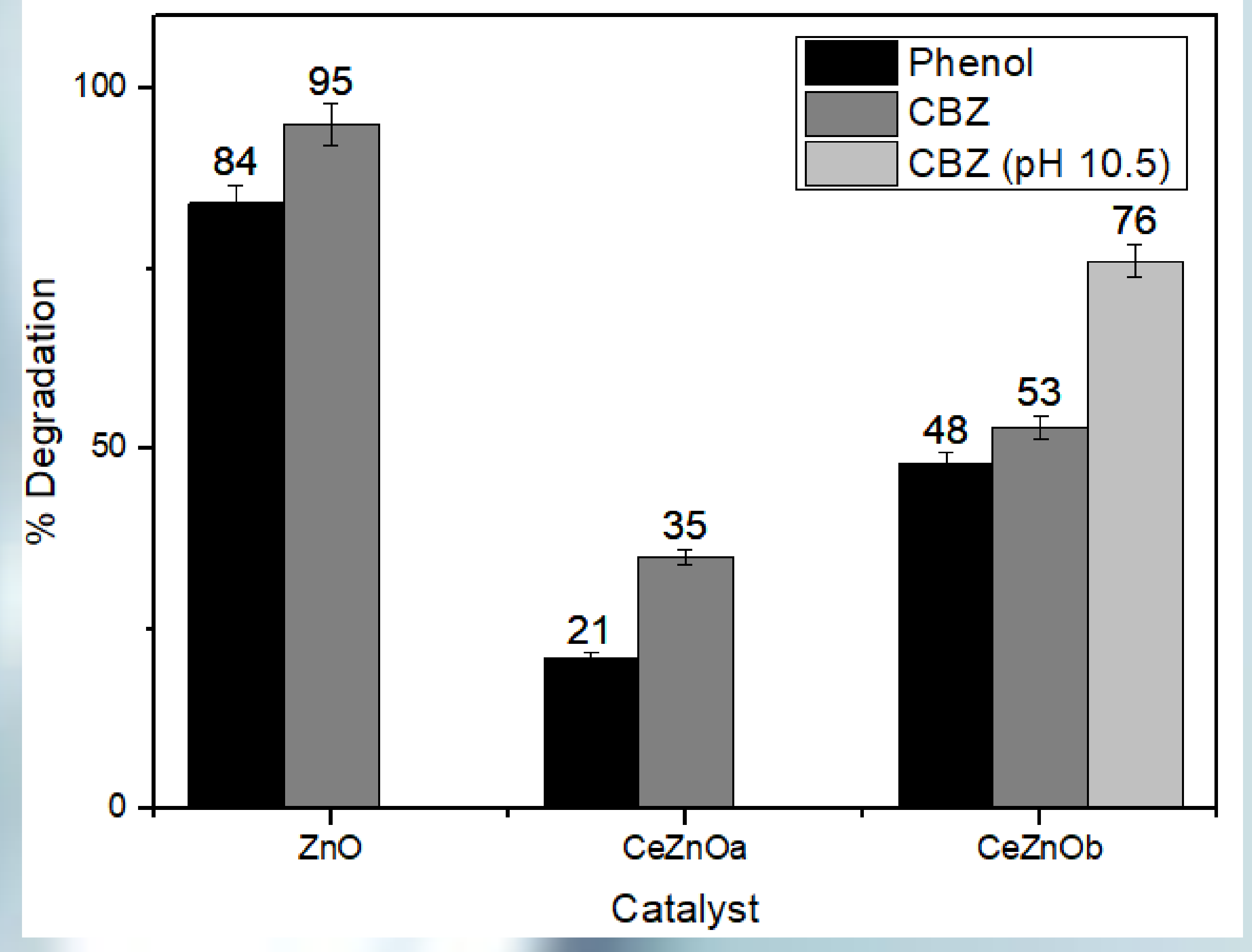

- Phenol was used as a test compound.

- The higher photocatalytic performance of CeZnOb compared to CeZnOa could and crystallinity.

and crystallinity.

direct photolysis in the absence of catalysts.

Photodissolution (ICP/MS)

\begin{tabular}{|l|c|}
\multicolumn{2}{|c|}{ Photodissolution (ICP/MS) } \\
\hline \multicolumn{1}{|c|}{ Essays } & $\mathrm{Zn}(\mathbf{m g} / \mathbf{L})(\mathbf{\varepsilon} \mathbf{0 , 6 \% )}$ \\
\hline $\mathrm{ZnO}($ dark $)$ & 2.8 \\
\hline $\mathrm{ZnO}(575 \mathrm{~nm})$ & 9.2 \\
\hline CeZnOa $(575 \mathrm{~nm})$ & 5.7 \\
\hline CeZnOb $(575 \mathrm{~nm})$ & 8.6 \\
\hline $\mathrm{CeZnOb+NaOH}(\mathrm{pH} 10.5)(575 \mathrm{~nm})$ & 4.8 \\
\hline
\end{tabular}

\section{REFERENCES}

1. López-Pacheco, I. Y. et al. Sci. Total Environ. 690, 1068

2. Hariharan, C. Appl. Catal. A-Gen. 304, 55-61 (2006).

CON ICET P 